\title{
Influence of Radiopacifying Agents on the Solubility, pH and Antimicrobial Activity of Portland Cement
}

\author{
Paulo Henrique WECKWERTH ${ }^{1}$ \\ Adriano Cosme de Oliveira MACHADO ${ }^{1}$ \\ Milton Carlos KUGA ${ }^{2}$ \\ Rodrigo Ricci VIVAN ${ }^{1}$ \\ Raquel da Silva POLLETO ${ }^{3}$ \\ Marco Antonio Hungaro DUARTE ${ }^{3}$
${ }^{1}$ Center of Health Sciences, USC - Sagrado Coração University, Bauru, SP, Brazil
${ }^{2}$ Department of Restorative Dentistry, Araraquara Dental School, UNESP - Univ Estadual Paulista, Araraquara, SP, Brazil USP - University of São Paulo, Bauru, SP, Brazil \\ ${ }^{3}$ Department of Dentistry, Endodontics and Dental Materials, Bauru Dental School,
}

\begin{abstract}
The aim of this study was to evaluate the interference of the radiopacifiers bismuth oxide (BO), bismuth carbonate (BC), bismuth subnitrate (BS), and zirconiun oxide (ZO) on the solubility, alkalinity and antimicrobial properties of white Portland cement (WPC). The substances were incorporated to PC, at a ratio of 1:4 (v/v) and subjected to a solubility test. To evaluate the $\mathrm{pH}$, the cements were inserted into retrograde cavities prepared in simulated acrylic teeth and immediately immersed in deionized water. The $\mathrm{pH}$ of the solution was measured at 3,24, 72 and $168 \mathrm{~h}$. The antimicrobial activity was evaluated by a radial diffusion method against the microorganisms S. aureus (ATCC 25923), P. aeruginosa (ATCC 27853), E. faecalis (ATCC 29212) and C. albicans (ATCC 10231). The zone of microbial growth inhibition was measured after $24 \mathrm{~h}$. The addition of BS and BC increased the solubility of the cement. The $\mathrm{pH}$ values demonstrated that all materials produced alkaline levels. At $3 \mathrm{~h}$, BS showed lower $\mathrm{pH}$ than WPC ( $<0.05)$. At $168 \mathrm{~h}$, all materials showed similar $\mathrm{pHs}(\mathrm{p}>0.05)$. The materials did not present antimicrobial activity for $S$. aureus, P. aeruginosas and E. faecalis $(\mathrm{p}>0.05)$. With regards to C. albicans, all materials formed an inhibition zone, mainly the mixture of WPC with ZO ( $<0.05)$. The type of radiopacifier incorporated into WPC interfered with its physical and antimicrobial properties. $\mathrm{ZO}$ was found to be a viable radiopacifier that can be used with WPC.
\end{abstract}

Key words: antimicrobial activity, Portland cement, radiopacifier, $\mathrm{pH}$.

\section{INTRODUCTION}

The use of MTA, based on scientific evidence and clinical studies, is directed to the treatment of accidents and endodontic complications $(1,2)$. The biocompatibility (3) and chemical composition $(4,5)$ of Portland cement (PC) are similar to those of MTA, except for the absence of bismuth. It has been proposed as an alternative material to retrograde root canal filling $(6,7)$, in substitution for MTA, since its physical properties are also comparable (8).

However, PC is less radiopaque than MTA (8), limiting its radiographic visualization after insertion in the apical cavity. In order to solve this problem, radiopacifier agents that are usually used in dental materials have been proposed to be aggregated into PC, such as bismuth oxide (BO) (9), bismuth carbonate (BC) (10), bismuth subnitrate (BS) (10) and zirconium oxide (ZO) (11). All the combinations provide greater dentin radiopacity (11) in accordance with the minimum values required by the American National Standards Institute and American Dental Association (ANSI/ ADA), specification No. 57 (12).

When evaluated by the radial diffusion method, PC did not present antimicrobial activity against Enterococcus faecalis $(13,14)$, Staphylococcus aureus, 
Escherichia coli and Candida albicans $(13,15)$.

Independent of PC type, bacterial infiltration occurred after 15 days of exposure to microorganisms. Therefore, the mean period of infiltration is approximately 45 days when the PC is in its structural form (16). Meanwhile, in current studies $(14,15)$ of antimicrobial activity, no additives or radiopacifiers were incorporated into white Portland cement (WPC).

The combination of $20 \%$ radiopacifier and $80 \%$ WPC (11) affects the final quantity of cement present in the mixture. Although the additions of BO, BC, BS and ZO provide better radiopacity tos $\mathrm{PC}(9-11)$, their effects on the solubility, alkalinization ability and antimicrobial activity in WPC is still unknown.

The addition of BO affects the dimensional stability, fluid absorption and solubility of MTA (17). The high level of water absorption (18), compromises its physicochemical properties (17). This brings up the question whether this is the ideal radiopacifier to be added to WPC (11), requiring the evaluation of other radiopacifiers that might not cause alterations in the solubility of the cement, making it recommendable for periapical surgery.

The $\mathrm{pH}$ of WPC with $20 \% \mathrm{BO}$ has been shown to be similar to that of white MTA Angelus ${ }^{\circledR}$, maintaining the alkaline level after $168 \mathrm{~h}$ evaluation (19). However, the influence of other radiopacifiers in the alkalinization capacity of WPC is unknown. ZO is a component of the epoxy-based cementAH Plus (Dentsply De Trey), which has a $\mathrm{pH}$ of approximately 7 . However, the influence of this radiopacifier in the $\mathrm{pH}$ of WPC has not yet been established.

The antimicrobial activity of WPC is well known (13-16). However, the incorporation of $20 \%$ of a radiopacifier to WPC would result in a final mixture with significant alterations in its composition, possibly causing changes in the antimicrobial potential, mainly against bacteria, such as $E$. faecalis, and the fungus $C$. albicans.

Given the need of obtaining an ideal radiopacifier for WPC, the aim of the present study was to verify the interference of $\mathrm{BO}, \mathrm{BC}, \mathrm{BS}$ and $\mathrm{ZO}$ incorporated into WPC in a 1:4 $(\mathrm{v} / \mathrm{v})$ ratio on cement solubility, $\mathrm{pH}$ at different periods and antimicrobial activity against 3 species of bacteria and 1 species of fungus.

\section{MATERIAL AND METHODS}

The following radiopacifiers were used: bismuth oxide (BO) (Synth, Diadema, SP, Brazil), bismuth carbonate (BC) (Synth), bismuth subnitrate (BS) (Synth) and zirconium oxide (ZO) (JB Química. Suzano, SP. Brazil). The used cement was WPC (Irajazinho; Cimentos Rio Branco AS, Rio de Janeiro, $\mathrm{RJ}$, Brazil). In all experiments, the proportion in volume of radiopacificier to WPC was in the ratio of 1 part $(20 \%)$ of radiopacifier to 4 parts $(80 \%)$ of WPC. To establish a workable material for dental applications, $1.0 \mathrm{~g}$ of powdered aggregate was incorporated to 0.3 $\mathrm{mL}$ of distilled water. As a control, the powdered WPC without radiopacifiers was also used with distilled water.

\section{Solubility Test}

The cement specimens were molded using Teflon ring molds $20 \mathrm{~mm}$ in diameter and $1.5 \mathrm{~mm}$ high. Three specimens were fabricated for each material. The mould was supported by a larger glass plate and covered with a cellophane sheet. An impermeable nylon thread was placed inside the material and another glass plate, also covered with cellophane film, was positioned on the mold and pressed manually in such a way that the plates touched the entire mold in a uniform manner. The assembly was placed in an incubator $\left(37^{\circ} \mathrm{C}, 95 \%\right.$ relative humidity) for a period corresponding to three times the setting time. Immediately after being removed from the mold, the specimens were left in a desiccator for $6 \mathrm{~h}$ and were then weighed three times each with a degree of accuracy of $0.0001 \mathrm{~g}$ (Sartorius scale model 1662; Sartorius, Gottingen, Germany), the mean reading being recorded. The specimens were suspended by the nylon thread and placed two-by-two inside plastic containers with a wide opening containing $50 \mathrm{~mL}$ of deionized water, with care to avoid any contact between them and the inner surface of the containers. The sealed containers were stored for $24 \mathrm{~h}$ in an incubator $\left(37^{\circ} \mathrm{C}\right.$, $95 \%$ relative humidity). After this period, the specimens were removed from the containers, rinsed with deionized distilled water, blotted dry with absorbent paper, placed in a desiccator for $24 \mathrm{~h}$ and then reweighed. The weight loss of each specimen (initial mass minus final mass) expressed as the percentage of the original weight, was taken as the solubility of the cement. According to the ANSI/ADA No. 57 specification (21) guideline, a root canal sealer should not have solubility greater than $3 \%$.

Data resulting form the tests were analyzed statistically by ANOVA and Tukey's test at a significance level of $5 \%$. 


\section{pH Analysis}

Fifty acrylic teeth with simulated root end cavities were used for the $\mathrm{pH}$ test. The teeth were divided into 5 groups ( $\mathrm{n}=10$ ), according to the tested material. The rootend cavities were filled with freshly prepared materials and the teeth were immediately sealed in glass flasks containing $15 \mathrm{~mL}$ of deionized water (Milli-Q water; Purelab Option DV25; Millipore Corp., Bellerica, MA, USA), and stored at $37^{\circ} \mathrm{C}$. After $3 \mathrm{~h}$ of immersion, the teeth were carefully removed and placed into new flasks with an equal amount of new deionized water, and this procedure was repeated after all predetermined periods: 24, 72 and $168 \mathrm{~h}$. After removal of the specimens, the glass flasks were vortexed for $5 \mathrm{~s}$ (Vortex Q-220A; Quimis Ap. Científicos Ltda., São Paulo, SP, Brazil) and the $\mathrm{pH}$ level of the solutions was analyzed using a pH meter (Quimis Ap. Científicos Ltda.) calibrated with a buffer solution ( $\mathrm{pH} 4.0,7.0$ and 12.0) at a constant temperature $\left(25^{\circ} \mathrm{C}\right)$. Data were compared by the ANOVA and Tukey's test at a significance level of 5\%.

\section{Antimicrobial Activity}

The technique used was radial diffusion, by evaluating the zone of microbial growth inhibition on Petri dishes containing Brain Heart Infusion (BHI) agar (Merck KGaA, Darmstadt, Germany) for the bacteria and Sabouraud dextrose agar (Merck KGaA) for the fungi. The bacteria used in the study were E. faecalis (ATCC 29212), S. aureus (ATCC 25923) and Pseudomonas aeruginosa (ATCC 27853) and the fungus was $C$. albicans (ATCC 10231).

After reactivation of the microorganisms and adjusting the optical density to match 0.5 on the McFarland scale $\left(1.5 \times 10^{8} \mathrm{CFU} \mathrm{mL}^{-1}\right), 20$ excavated (6 mm diameter $\times 3 \mathrm{~mm}$ depth) Petri dishes (5 per microorganism) were inoculated and incubated at $37^{\circ} \mathrm{C}$ for additional $30 \mathrm{~min}$. WPC and the 4 experimental cements containing the radiopacifiers $(\mathrm{BO}, \mathrm{BC}, \mathrm{BS}$ and $\mathrm{ZO}$ ) were taken individually to each excavation with a Luer syringe. After $2 \mathrm{~h}$ of pre-incubation at room temperature, the cultures were maintained in an oven at $37^{\circ} \mathrm{C}$ for $24 \mathrm{~h}$.

After this period, the zone of microbial growth inhibition was measured with a digital caliper accurate to the nearest $0.01 \mathrm{~mm}$ (Mitutoyo Corporation, Tokyo, Japan). The experiment was performed five times for each species of microorganism. Cellulose disks moistened with $2 \%$ chlorhexidine digluconate (CHX) or sterile saline solution (SS) were placed on the culture medium, being the positive and negative control, respectively. The inhibition zone measurement of the antimicrobial activity provided by the $2 \% \mathrm{CHX}$ was $13.0 \mathrm{~mm}$ and $0.0 \mathrm{~mm}$ for the SS.

The results obtained with the cements were submitted to ANOVA and Tukey's testing at a significance level of $5 \%$.

\section{RESULTS}

Table 1 contains the mean and standard deviation of the solubility of WPC and the experimental cements. Only BS and BC increased significantly the solubility of WPC ( $p<0.05)$. The solubility of WPC may increase according to the type of radiopacifier used, with the exception of ZO.

After the immersion of the specimens and evaluation of the $\mathrm{pH}$ level of ultrapure water during the determined time periods, it was observed that the radiopacifiers interfered with the $\mathrm{pH}$ of WPC. Table 2 contains the mean and standard deviation of the $\mathrm{pH}$ level values shown in the cements. Within $3 \mathrm{~h}$, only WPC/BS showed a lower $\mathrm{pH}$, and significant differences $(\mathrm{p}<0.05)$ in WPC. Inversely, within $24 \mathrm{~h}$, the WPC/BS showed a higher $\mathrm{pH}$ level, significantly different $(\mathrm{p}<0.05)$ from WPC/ZO. At the $72 \mathrm{~h}$ analysis period, the highest $\mathrm{pH}$ occurred for WPC/BS, followed by WPC/BO and WPC, showing significant differences $(\mathrm{p}<0.05)$ in $\mathrm{WPC} / \mathrm{ZO}$ and WP/BC. Meanwhile, after $168 \mathrm{~h}$ of evaluation the cements displayed similar $(\mathrm{p}>0.05) \mathrm{pH}$ levels.

Table 3 demonstrates the mean and standard deviation of the zone of microbial growth inhibition

Table 1. Means (in mg) and standard deviations of the solubility of the tested cements.

\begin{tabular}{ll}
\hline Cement & Solubility \\
\hline WPC & $0.91(0.12)^{\mathrm{a}}$ \\
WPC/BO & $1.16(0.02)^{\mathrm{a}}$ \\
$\mathrm{WPC} / \mathrm{BC}$ & $5.29(0.16)^{\mathrm{b}}$ \\
$\mathrm{WPC} / \mathrm{BS}$ & $8.30(1.14)^{\mathrm{c}}$ \\
$\mathrm{WPC} / \mathrm{ZO}$ & $0.58(0.33)^{\mathrm{a}}$ \\
\hline
\end{tabular}

WPC: White Portland cement. BO: Bismuth oxide. BC: Bismuth carbonate. BS: Bismuth subnitrate. ZO: Zirconium oxide. Different letters in columns indicate statistically significant difference $(\mathrm{p}<0.05)$. 
produced by the cements. The means of the zone of microbial growth inhibition shown by the $2 \% \mathrm{CHX}$ was $13.0 \mathrm{~mm}$. There was no inhibition activity in the saline solution. In the evaluation of the antimicrobial activity by the radial diffusion method, none of the cements inhibited the microbial growth of E. faecalis, S. aureus and $P$. aeruginosa $(\mathrm{p}>0.05)$. On the other hand, C. albicans was inhibited by all cements, with WPC/ZO providing the largest zone of microbial inhibition $(\mathrm{p}<0.05)$.

\section{DISCUSSION}

The addition of $20 \%$ radiopacifiers interfered with the physical and microbiological properties of WPC. BC and BS increased the solubility of WPC. The alkalinization ability undergoes interference, depending on the analysis period and the type of radiopacifier. BO did not interfere with the alkalinization ability of the WPC during all the analyzed periods. BS reduced the $\mathrm{pH}$ already in the first $3 \mathrm{~h}$. BC and $\mathrm{ZO}$ reduced the $\mathrm{pH}$ of WPC within $72 \mathrm{~h}$. However, the $\mathrm{pH}$ of all cements was similar to that of WPC within $168 \mathrm{~h}$ (7 days) of the evaluation. The cements did not demonstrate antimicrobial activity against the analyzed microorganisms, except for $C$. albicans, mainly WPC/ZO.

In the solubility test, the combination of WPC with BC and BS did not comply with the ADA's standards (12), which stipulate a maximum of $3 \%$ mass difference. BO is the radiopacifier used in MTA (1). When incorporated into WPC, an alteration occurs in the

Table 2. Means and standard deviations of the $\mathrm{pH}$ of the cements at the different evaluation times.

\begin{tabular}{lcccc}
\hline Cement & $3 \mathrm{~h}$ & $24 \mathrm{~h}$ & $72 \mathrm{~h}$ & $168 \mathrm{~h}$ \\
\hline WPC & 13.54 & 8.85 & 8.63 & 8.14 \\
& $(0.98)^{\mathrm{a}}$ & $(0.93)^{\mathrm{ab}}$ & $(0.84)^{\mathrm{a}}$ & $(0.88)^{\mathrm{a}}$ \\
WPC/BO & 11.45 & 8.99 & 8.78 & 7.93 \\
& $(1.13)^{\mathrm{ab}}$ & $(0.94)^{\mathrm{ab}}$ & $(0.69)^{\mathrm{a}}$ & $(0.67)^{\mathrm{a}}$ \\
WPC/BC & 11.32 & 8.98 & 7.68 & 7.94 \\
& $(1.39)^{\mathrm{ab}}$ & $(0.78)^{\mathrm{ab}}$ & $(0.26)^{\mathrm{b}}$ & $(0.66)^{\mathrm{a}}$ \\
WPC/BS & 10.59 & 9.26 & 9.26 & 8.32 \\
& $(1.34)^{\mathrm{b}}$ & $(1.10)^{\mathrm{b}}$ & $(0.77)^{\mathrm{a}}$ & $(0.76)^{\mathrm{a}}$ \\
WPC/ZO & 11.24 & 7.91 & 7.61 & 7.62 \\
& $(1.48)^{\mathrm{ab}}$ & $(0.69)^{\mathrm{a}}$ & $(0.18)^{\mathrm{b}}$ & $(0.31)^{\mathrm{a}}$ \\
\hline
\end{tabular}

WPC: White Portland cement. BO: Bismuth oxide. BC: Bismuth carbonate. BS: Bismuth subnitrate. ZO: zirconiun oxide. Different letters in columns indicate statistically significant difference $(p<0.05)$. hydration process (18) and causes structural failure (11).

During the setting time of $\mathrm{PC}$, an expansion of the material occurs due to the hydration process $(8,18)$. There are space formations within the cement matrix, which originate from the absorption of water $(1,18)$. With the evolution of the process, initially these particles tend to leave empty spaces in the structure and eventually form components. In the next phase, the hydration process causes an increase of solid volume, reducing the porosity and the final mass when compared initially $(2,18)$. In this study, the solubility test of cements was recorded only after the final setting, discounting the interference of this process the along the way.

$\mathrm{BC}$ and $\mathrm{BS}$ are excipients used in oral medications. Only the cements incorporated with these radiopacifiers displayed greater solubility than WPC, similar to bismuth increasing the absorption of water in WPC (18) and in the solubility test, dehydration occurred with the specimens to obtain the final weight (12), and the mass reduction was always evident.

Probably because of the natural reaction of hydration, the presence of $\mathrm{BC}$ and $\mathrm{BS}$ interfered with the structure and final weight of the WPC. ZO is one of the components of the endodontic cement AHPlus (Dentsply DeTrey GmbH. Konstanz, Germany), and displayed the least interference with the solubility of WPC.

Differing from the solubility test, the evaluation of the alkalinization capacity $(\mathrm{pH})$ of the cements started immediately after mixing, which made impossible establishing a correlation between the tests. In the $\mathrm{pH}$

Table 3. Means and standard deviation (in $\mathrm{mm}$ ) of the zones of microbial growth inhibition for the tested cements.

\begin{tabular}{lcccc}
\hline Cement & $\begin{array}{c}S . \\
\text { aureus }\end{array}$ & $\begin{array}{c}E . \\
\text { faecalis }\end{array}$ & $\begin{array}{c}P . \\
\text { aeruginosa }\end{array}$ & $\begin{array}{c}C . \\
\text { albicans }\end{array}$ \\
\hline WPC & $0^{\mathrm{a}}$ & $0^{\mathrm{a}}$ & $0^{\mathrm{a}}$ & 6.75 \\
& & & & $(0.50)^{\mathrm{a}}$ \\
WPC/BO & $0^{\mathrm{a}}$ & $0^{\mathrm{a}}$ & $0^{\mathrm{a}}$ & 7.50 \\
& & & & $(0.57)^{\mathrm{a}}$ \\
WPC/BC & $0^{\mathrm{a}}$ & $0^{\mathrm{a}}$ & $0^{\mathrm{a}}$ & 7.50 \\
& & & & $(0.57)^{\mathrm{a}}$ \\
WPC/BS & $0^{\mathrm{a}}$ & $0^{\mathrm{a}}$ & $0^{\mathrm{a}}$ & 7.00 \\
& & & & $(0.00)^{\mathrm{a}}$ \\
$\mathrm{WPC} / \mathrm{ZO}$ & $0^{\mathrm{a}}$ & $0^{\mathrm{a}}$ & $0^{\mathrm{a}}$ & 9.00 \\
& & & & $(0.81)^{\mathrm{b}}$ \\
\hline
\end{tabular}

WPC: White Portland cement. BO: Bismuth oxide. BC: Bismuth carbonate. BS: Bismuth subnitrate. ZO: zirconiun oxide. Different letters in columns indicate statistically significant difference $(p<0.05)$. 
analysis, for all hydration processes, expansion and eventual migration of byproducts to the surface of the cements should be considered (2). Inversely, the solubility test showed that the specimens had already concluded the setting.

The higher solubility observed for BS and BC can be related to the negative interference of these substances with the hydration of WPC, increasing the porosity of the material and consequently its solubility.

Although BC and BS showed a higher solubility, this property did not implicate in an increase of the $\mathrm{pH}$ level after $72 \mathrm{~h}$. Perhaps the formation of calcium hydroxide and the release of hydroxyl ions does not occur during the solubility stage, but a release of other components such as bismuth does.

Independent of the evaluation period, the cements promoted alkalinization of the ultrapure water, reducing the $\mathrm{pH}$ during the experiment. The $\mathrm{pH}$ of the ultrapure water where WPC and WPC/BO were immersed always maintained alkaline levels, showing a marked reduction after $24 \mathrm{~h}$ of analysis. Similar results were also observed in other studies $(18,19)$. Camilleri $(18)$ found lower $\mathrm{pH}$ values for WPC/BO in the first $24 \mathrm{~h}$, whereby the evaluation was done directly on cement surface. This possibly resulted when the calcium hydroxide formed during the process of hydration reacted with the carbon dioxide in the air, forming calcium carbonate.

Some differences of $\mathrm{pH}$ were observed among the experimental cements during the evaluation times, but after $168 \mathrm{~h}$ ( 7 days) all values were similar, agreeing with the results when compared with WMTA Angelus ${ }^{\circledR}$ and WPC/BO (19). In this study, the ultrapure water was replaced for each experimental period, avoiding saturation in the middle. Due to the hydration reaction in the setting of WPC, a portion of the formed calcium hydroxide could have dissolved in the liquids. This replacement of new ultrapure water was favored exclusively in the evaluation of the alkalinization ability of the cement within the determined analyzed period. This justified the similar values of $\mathrm{pH}$ after $168 \mathrm{~h}$, probably because the formation of calcium hydroxide is reduced after the final setting of the cement (19).

The evaluation method of antimicrobial activity was the radial diffusion in agar. This methodology is used in the literature as one of the initial tests to verify antimicrobial activity of the material against certain microorganisms $(13,15)$. E. faecalis and C. albicans are frequently associated with endodontic failures and used as a parameter for material comparisons $(13,16)$.
The antimicrobial activity of WPC and the experimental cements did not occur in relation to all types of bacteria used in the present study, agreeing with the results of other authors that tested PC against $S$. aureus, E. faecalis and E. coli (13). On the other hand, the cements displayed antimicrobial activity against $C$. albicans, providing zones of microbial growth inhibition varying from $6.75 \mathrm{~mm}$ to $9.0 \mathrm{~mm}$, smaller than the zone produced by the positive control ( $2 \% \mathrm{CHX})$. ZO provided a greater microbial inhibition zone when compared with the other cements $(\mathrm{p}<0.05)$.

Estrela et al. (15) did not observe inhibition zones of microbial growth when testing gray PC. However, considering other studies on the antifungal activity of PC $(13,15,16)$, only the present study evaluated the effectiveness of WPC added with diverse radiopacifiers. The difference of the results of this study and other studies $(13,16)$ in relation to the efficacy of WPC against C. albicans, is probably due to the microorganism used in the study. While this study used C. albicans ATCC 10231, the other studies $(13,16)$ used C. albicans ICB/ USP-562, which can be more resistant to WPC.

The use of MTA in Endodontics is well established (2), with favorable results and prognostics (1). The chemical similarity of MTA with WPC is indisputable (4), presenting similar biological results (3). Meanwhile, its radiopacity is lower (11) than that recommended by the American Dental Association (ADA) No. 57 specification (12). The addition of a radiopacifier, such as BO, is recommended (18), regardless of occasional negative interferences in the cement's physical properties $(17,18)$. In this proposal, BS, BC and ZO, in spite of being poorly studied radiopacifiers, can be considered as an alternative (11).

According to its low solubility, final alkalinization potential and antimicrobial activity similar to WPC, makes $\mathrm{ZO}$ a promising radiopacifier agent to be used as an aggregate for WPC, at the proportion of $20 \%$ volume in WPC. The reduction of the $\mathrm{pH}$ of WPC with $\mathrm{ZO}$ after $24 \mathrm{~h}$ is related to the lower solubility of this association. Possibly the zirconium oxide participates effectively in the hydration of PC, favoring a more homogeneous cement with less porosities. Other studies must be conducted with this combination to finally verify cement expansion, intensity of water absorption, material resistance and biological compatibility.

In summary, WPC represents an alternative material to be used as a retrograde filling material. The addition of $20 \%$ ZO in volume to WPC resulted in less 
solubility when compared with $\mathrm{BC}$ and $\mathrm{BS}$, similar to pure WPC. The alkalinization capacity was similar to that of WPC, and therefore the antimicrobial activity against C. albicans was superior to that of the other cements. However, with regard to the methodologies used in the present study and according to the interpretation of the obtained results, it may be concluded that the radiopacifiers $\mathrm{BS}$ and $\mathrm{BC}$ had a negative influence on WPC, while ZO did not affect the results of WPC, appearing as a promising radiopacifier to be investigated.

\section{REFERENCES}

1. Torabinejad M, Parirokh M. Mineral trioxide aggregate: A comprehensive literature review - Part II: Leakage and biocompatibility investigations. J Endod 2010;36:190-202.

2. Parirokh M, Torabinejad M. Mineral trioxide aggregate: A comprehensive literature review - Part III: Clinical applications, drawbacks, and mechanism of action. J Endod 2010;36:400-413.

3. Martínez Lalis R, Esain ML, Kokubu GA, Willis J, Chaves C, Grana DR. Rat subcutaneous tissue response to modified Portland cement, a new mineral trioxide aggregate. Braz Dent J 2009;20:112-117.

4. Oliveira MG, Xavier CB, Demarco FF, Pinheiro ALB, Costa AT, Pozza DH. Comparative chemical study of MTA and Portland cements. Braz Dent J 2007;18:3-7.

5. Asgary S, Eghbal MJ, Parirokh M, Ghoddsi J, Kheirieh S, Brink F. Comparison of mineral trioxide aggregate's composition with Portland cements and a new endodontic cement. J Endod 2009;35:243-250.

6. Bidar M, Moradi S, Jafarzadeh H, Bidad S. Comparative SEM study of the marginal adaptation of white and grey MTA and Portland cement. Aust Endod J 2007;33:2-6.

7. Valera MC, Camargo CHR, Carvalho AS, Gama ERP. In vitro evaluation of apical microleakage using different root-end filling materials. J Appl Oral Sci 2006;14:49-52.

8. Islam I, Chng HK, Yap AU. Comparison of the physical and mechanical properties of MTA and Portland cement. J Endod 2006;32:193-197.

9. Vivan RR, Ordinola-Zapata R, Bramante CM, Bernadinelli N, Garcia RB, Duarte MAH, et al.. Evaluation of the radiopacity of some commercial and experimental root-end filling materials. Oral Surg Oral Med Oral Pathol Oral Radiol Endod 2009;108:e35-e38.

10. Bortoluzzi EA, Guerreiro-Tanomaru JM, Tanomaru-Filho M, Duarte MAH. Radiographic effect of different radiopacifiers on a potential retrograde filling material. Oral Surg Oral Med Oral Pathol Oral Radiol Endod 2009;108:628-632.

11. Duarte MAH, El Kadre GDO, Vivan RR, Guerreiro-Tanomaru JM, Tanomaru-Filho M, Moraes IG. Radiopacity of Portland cement associated with different radiopacifying agents. J Endod 2009;35:737-740.

12. American Dental Association. Specification No. 57 for endodontic filling materials. J Am Dent Assoc 1984;108:88.

13. Miyagak DC, Carvalho EMOF, Robazza CRC, Chavasco JK, Levorato GL. In vitro evaluation of the antimicrobial activity of endodontic sealers. Braz Oral Res 2006;20:303-306.

14. Ribeiro CS, Kuteken FA, Hirata Júnior R, Scelza MFZ. Comparative evaluation of antimicrobial action of MTA, calcium hydroxide and Portland cement. J App Oral Sci 2006;14:330-333.

15. Estrela C, Bammann LL, Estrela CR, Silva RS, Pécora JD Antimicrobial and chemical study of MTA, Portland cement, calcium hydroxide paste, Sealapex and Dycal. Braz Dent J 2000;11:3-9.

16. Estrela C, Estrada-Bernabé PF, Almeida-Decurcio D, AlmeidaSilva J, Rodrigues-Araújo-Estrela C, Poli-Figueiredo JA. Microbial leakage of MTA, Portland cement, Sealapex and zinc oxide-eugenol as root-end filling materials. Med Oral Patol Oral Cir Bucal 2011;1:e418-e424.

17. Camilleri J. Evaluation of the effect of intrinsic material properties and ambient conditions on the dimensional stability of white mineral trioxide aggregate and Portland cement. J Endod 2011;37:239-245.

18. Camilleri J. The physical properties of accelerated Portland cement for endodontic use. Int Endod J 2008;41:151-157.

19. Vivan RR, Ordinola-Zapata R, Zeferino MA, Bramante CM, Bernadineli N, Garcia RB, et al.. Evaluation of the physical and chemical properties of two commercial and three experimental root-end filling materials. Oral Surg Oral Med Oral Pathol Oral Radiol Endod 2010;110:250-256.

20. Duarte MAH, Demarchi ACO, Moraes IG. Determination of $\mathrm{pH}$ and calcium ion release provided by pure and calcium hydroxidecontaining AH Plus. Int Endod J 2004;37:42-45.

Received May 22, 2012 Accepted October 31, 2012 